\title{
Association between number of medications used and nutritional markers among elderly persons with chronic diseases: National Health Survey (2013)
}

Isabel Cristina Bento',2 (ID

Mary Anne Nascimento Souza, ${ }^{1,2}$ (D) Sérgio Viana Peixoto $0^{1,2,3} \mathbb{D}$

\section{Abstract}

Objective: to evaluate the association between the number of medications taken and nutritional markers in Brazilian elderly persons diagnosed with chronic diseases. Method: study based on data from the National Health Survey (PNS) 2013, for the population aged 60 years or older who reported at least one chronic disease (hypertension, diabetes mellitus, heart disease, stroke, arthritis, depression, lung disease and chronic renal failure) (7,770 elderly persons). The outcome was the number of medications used for the selected diseases $(0,1$ to 2 and 3 or more), and the exploratory variables were food consumption markers and anthropometric indicators (body mass index, waist circumference and waist-to-height ratio). The associations were evaluated by multinomial logistic regression, estimating the odds ratio and confidence intervals (95\%) and considering potential confounding factors. Results: the use of a greater number of medications was positively associated with the consumption of fruits and vegetables, fish and milk, and negatively associated with the consumption of sweet foods, soft drinks and meat with excess fat; a greater consumption of medications was also associated with higher anthropometric indicator values. Conclusion: although a greater consumption of medications was associated with better dietary indicators, these elderly persons also had higher anthropometric indicator values, including a higher concentration of central adiposity.

\footnotetext{
Instituto René Rachou, Núcleo de Estudos em Saúde Pública e Envelhecimento. Belo Horizonte, Minas Gerais, Brasil.

2 Instituto René Rachou, Programa de Pós-Graduação em Saúde Coletiva. Belo Horizonte, Minas Gerais, Brasil.

3 Universidade Federal de Minas Gerais, Escola de Enfermagem, Departamento de Enfermagem Aplicada. Belo Horizonte, Minas Gerais, Brasil.

Keywords: Health of the Elderly. Drug Utilization. Food Consumption. Nutritional Status. Health Surveys. 


\section{INTRODUCTION}

Population aging has contributed to an increase in the prevalence of Chronic Non-communicable Diseases (CNCD) and, consequently, a growth in the concomitant use of various medications. The intake of multiple medications can affect eating behavior and, consequently, nutrient absorption, contributing to the emergence of nutritional disorders in the elderly and increased morbidity and mortality among this group ${ }^{2,3}$. However, there is also evidence that poor nutritional status leads to a need for the prescription of multiple medications, causing a vicious cycle that causes significant health impacts among this population ${ }^{3}$.

However, the association between the use of different medications and the nutritional status of the elderly has not yet been fully established in literature ${ }^{4,5}$. Nevertheless, evidence shows that medication use is associated with changes in food intake ${ }^{6}$ and various nutritional disorders, such as weight loss ${ }^{7}$ and obesity ${ }^{5}$. These findings demonstrate that, even if the actual temporal relationship between these events is unknown, there exists a synergistic relationship between them, leading to the greater vulnerability of the elderly when using multiple medications and/or undergoing nutritional deficiencies, which should be addressed by health services ${ }^{2,3,8,9}$.

In this context, and based on the understanding that healthy eating may be a fundamental nonpharmacological measure for the treatment of chronic diseases $^{6}$, it is important to study the association between the use of polypharmacy, diet and nutritional status, especially in the population with CNCD, which is still little explored in Brazil'. This knowledge may help the multiprofessional teams that accompany this group of elderly people when proposing interventions and so avoid other health complications ${ }^{3}$. The objective of the present study was therefore to verify whether markers of food consumption and anthropometric indicators vary in relation to the number of medications consumed by Brazilian elderly persons diagnosed with chronic non-communicable diseases.

\section{METHODS}

\section{Study population}

A cross-sectional study was performed using data from the National Health Survey (PNS), carried out throughout Brazil in 2013 by the Brazilian Institute of Geography and Statistics (IBGE), in partnership with the Ministry of Health and the Oswaldo Cruz Foundation (FIOCRUZ). The National Health Survey was approved by the National Commission for Research Ethics (CONEP) in 2013 (Process $n^{\circ}$ 328.1590) and all the participants signed a free and informed consent form ${ }^{10}$.

Sampling was carried out in three stages: the primary units were the IBGE census tracts, the secondary units were the households located in these sectors and the tertiary units were the randomly selected adult residents among all the eligible individuals aged 18 years and over residing in the sampled household. The data were collected through structured questionnaires and physical measurements, which were performed in the sampled households ${ }^{11}$.

For the present study, 7,770 participants aged 60 years or older were selected, who reported having at least one of the following CNCDs: arterial hypertension, diabetes mellitus, heart disease, cerebral vascular accident or stroke, arthritis or rheumatism, depression, lung diseases and chronic renal failure. The diagnosis of these diseases was ascertained by the question "Have you ever been diagnosed with ... by a doctor?" for each of the above mentioned chronic conditions. For depression, the question "Has a doctor or mental health professional psychiatrist or psychologist ever diagnosed you as suffering from depression?" The variable number of chronic diseases was used to characterize the sample included in the analysis.

\section{Variables and collection procedures}

The outcome of interest (dependent variable) was the number of medications used for the selected chronic diseases. Following an affirmative answer regarding the presence of the disease, respondents 
were asked about the use of medications for each of these conditions: "In recent weeks have you taken medications because of arterial hypertension (high blood pressure??"; "In the past two weeks, because of diabetes did you: (I) take oral medications to lower your blood sugar levels (II) use insulin?". For the other conditions, the question was: "What do you currently do because of...?", "Do you take medication?". The participants were then classified into three groups: did not use medication, used medication for one to two chronic diseases, used medication for three or more reported chronic diseases.

The independent or exploratory variables were the markers of food consumption (fruits and vegetables, fish, beans, sweet foods, soft drinks or artificial juices, milk, salt and fatty meat) and anthropometric indicators (body mass index [BMI] ,waist circumference [WC] and waist to height ratio [WHR]). The intake of fruits and vegetables was evaluated by the weekly frequency of the intake of fruit and/or lettuce and tomato salad or salad of any other vegetable or raw legume and/or vegetables or cooked vegetables (except potatoes, cassava or yams), with a minimum frequency of five times a day, at least five days a week considered the recommended intake of these foods. The regular intake of fish (once or more per week), as well as of beans ${ }^{12}$, sweet foods and soft drinks/ artificial juice (five or more days per week) were also considered. To evaluate milk intake, the type of milk consumed (not consumed, full-fat milk, skimmed or semi-skimmed consumed) was considered. Salt intake was assessed by the individual's perception of freshly prepared food and processed foods (adequate/low/very low and high/ very high). The intake of fatty meat was evaluated by the report of the intake of red meat and/or chicken, without removing the visible excess fat or the skin, respectively ${ }^{13}$.

The anthropometric indicators were estimated by direct measurements, obtained by standardized equipment and techniques, while the individual was standing erect and unassisted. To measure weight, a portable digital scale was used, and for the measurement of height a portable stadiometer was employed. The individuals stood upright, were barefoot, wore light clothing and removed any accessories (glasses, belts, necklaces, etc.) or objects (purse, wallet, cell phone, etc.). Waist circumference
(WC) was measured using a non-elastic and flexible tape measure. The reading was made at the midpoint between the last rib and the iliac crest at the end of a normal exhalation. BMI was defined as the ratio of weight in kilograms to the square of the height in meters $\left(\mathrm{kg} / \mathrm{m}^{2}\right)$. The waist-to-height ratio (WHR) was obtained by dividing the WC by height $(\mathrm{cm})$. To facilitate the interpretation of the measures of association (multinomial logistic regression), the WHR was multiplied by $10^{14}$.

Potential confounding factors included sociodemographic characteristics (gender, marital status and schooling), health behaviors (alcohol consumption, current smoking and physical activity in leisure time), health conditions (self-assessment of health) and number of medical visits in the last 12 months. Alcohol intake was categorized as "nonintake", light/moderate intake (between one and seven units/week for women and one to 14 units/ week for men) and at-risk intake (more than seven units/week for women and more than 14 units/week for men), based on the reference values proposed by the National Institute on Alcohol Abuse and Alcoholism ${ }^{15}$. Current smoking was assessed by the current consumption of any tobacco product (no/ yes) regardless of frequency. Elderly persons who carried out at least 150 minutes of mild or moderate physical activity or at least 75 minutes of vigorous weekly physical activity in their leisure time were considered physically active ${ }^{16}$. The use of health services and health condition variables included the number of medical visits in the last 12 months prior to the interview (less than three and four or more visits) and self-assessment of health (good/excellent, fair and poor/very poor).

\section{Data analysis}

A description of all the variables included in the study was carried out for the total population, based on the categories of medication intake considered. The comparison of the distribution of these variables between the categories of the dependent variable was performed using the Pearson chi-squared test (categorical variables) or linear regression (continuous variables). 
Multinomial logistic regression was used to obtain estimates of the odds ratios (OR) and their respective $95 \%$ confidence intervals in order to verify the association between medication use and markers of nutritional condition. Three models were constructed, with the progressive inclusion of the confounding variables: the first model included the sociodemographic variables (gender, age, marital status and schooling); in the second model the variables of health behavior (alcohol consumption, current smoking and practice of physical activity in leisure time) were added; in the final model, the number of health appointments in the last 12 months and self-assessment of health were added.

The Stata ${ }^{\circledR}$ (StataCorp LLP, College Station, Texas, USA) version 13.0 software package was used for all the analyses, taking into consideration the complexity of the National Health Survey sample $\operatorname{plan}^{12}$.

\section{RESULTS}

Among the 11,697 elderly participants of the National Health Survey, 10,537 included information on the selected variables and 7,770 reported having one or more chronic disease and were included in the present analysis. Of these, $17.6 \%$ (95\% CI: 16.2-19.2\%) did not use medications for the diseases selected, $71.1 \%$ (95\% CI: $69.3-72.8 \%$ ) used medications for one two of these diseases, and 11.3\% (95\% CI: 10.112.6) used medications for three or more diseases.

Table 1 shows the characteristics of the population studied and their distribution according to the number of medications consumed, among Brazilian elderly persons with CNCD. There was a predominance of female, younger, married individuals, with a low level of education, who did not use alcohol or tobacco, were not active in their leisure time, had less than four health appointments in the previous 12 months, and had a fair self-perception of health and two or more chronic diseases. The number of medications consumed had a significant association $(p<0.05)$ with gender, age, alcohol intake, current smoking, number of medical consultations, self-assessment of health and number of chronic diseases investigated.
Table 2 shows the distribution of food consumption markers and anthropometric indicators for the total population and according to the number of medications used, among Brazilian elderly persons with CNCD. There was a predominance of elderly people who did not meet the recommended intake of fruits and vegetables but regularly ate fish and beans. The majority of the elderly consumed sweet foods and soft drinks on fewer than five days per week and had a greater consumption of full-fat milk. There was a predominance of elderly persons who reported the fair, low, or very low consumption of salt and who did not eat fatty meat. The mean and standard deviation variables for the anthropometric indicators are shown in the table. In general, the groups that reported taking medications had significantly higher proportions of fruit/vegetable and skimmed/semiskimmed milk intake, as well as lower consumptions of sweet foods, soft drinks or artificial juices and meat with excess fat. On the other hand, the mean BMI, CC and WHR values were significantly higher in these groups, compared to elderly persons who did not report using medications for the selected chronic diseases.

Table 3 shows the associations between the number of medications consumed and the markers of food consumption and anthropometric indicators, with and without adjustment for the confounding variables considered in the study, among Brazilian elderly persons with CNCD. Considering the model adjusted for all the confounding factors included in the study (Model 3), it was observed that the elderly persons who used three or more medications had a greater chance of consuming fruits and vegetables five or more times a day on five or more days/week, fish on one or more days/week and full-fat or skimmed milk, in addition to a lower chance of consuming sweet foods on five or more days/week and fatty meat. Elderly persons who consumed one to two medications had a lower chance of consuming sweet foods and soft drinks or artificial juice on five or more days/week and fatty meat, as well as a greater chance of consuming skimmed/ semi-skimmed milk. The anthropometric indicators exhibited a consistent association in both groups, regardless of the confounding factors considered, with higher values among the elderly who reported taking any number of medications. 
Table 1. Socio-demographic characteristics, health behaviors, health conditions and use of health services among Brazilian elderly persons, according to the number of medications consumed. National Health Survey (2013).

\begin{tabular}{|c|c|c|c|c|c|}
\hline \multirow[t]{2}{*}{ Variables } & \multirow{2}{*}{$\begin{array}{l}\text { Total } \\
(\%)\end{array}$} & \multicolumn{3}{|c|}{ Use of medication $(\%)$} & \multirow[t]{2}{*}{ Value $p^{1}$} \\
\hline & & None & 1 to 2 & 3 or more & \\
\hline Gender & & & & & $<0.001$ \\
\hline Female & 59.0 & 45.9 & 62.1 & 60.4 & \\
\hline Male & 41.0 & 54.1 & 37.9 & 39.6 & \\
\hline Age in years & & & & & 0.009 \\
\hline $60-69$ & 54.5 & 61.7 & 53.5 & 49.0 & \\
\hline $70-79$ & 31.0 & 25.5 & 31.8 & 35.0 & \\
\hline 80 or + & 14.5 & 12.8 & 14.7 & 16.0 & \\
\hline Marital status & & & & & 0.969 \\
\hline Married & 53.2 & 53.3 & 53.3 & 52.6 & \\
\hline Unmarried & 46.8 & 46.7 & 46.7 & 47.4 & \\
\hline Schooling & & & & & 0.162 \\
\hline Secondary or above & 20.0 & 17.5 & 20.9 & 18.0 & \\
\hline Primary or below & 80.0 & 82.5 & 79.1 & 82.0 & \\
\hline Alcohol intake ${ }^{2}$ & & & & & $<0.001$ \\
\hline Non-intake & 87.4 & 80.9 & 88.3 & 92.3 & \\
\hline Mild/moderate intake & 8.5 & 11.4 & 8.2 & 5.9 & \\
\hline At risk intake & 4.1 & 7.7 & 3.5 & 1.8 & \\
\hline Current smoker & & & & & $<0.001$ \\
\hline No & 88.4 & 76.8 & 91.2 & 88.5 & \\
\hline Yes & 11.6 & 23.2 & 8.8 & 11.5 & \\
\hline Physical activity in leisure time & & & & & 0.613 \\
\hline Active $^{3}$ & 13.0 & 12.0 & 13.4 & 12.3 & \\
\hline Inactive & 87.0 & 88.0 & 86.6 & 87.7 & \\
\hline $\begin{array}{l}\text { Number of medical appointments in } \\
\text { previous } 12 \text { months }\end{array}$ & & & & & $<0.001$ \\
\hline 0 to 3 & 53.7 & 73.4 & 53.0 & 26.6 & \\
\hline$\geq 4$ & 46.3 & 26.6 & 47.0 & 73.4 & \\
\hline Self-perception of health & & & & & $<0.001$ \\
\hline Good/excellent & 36.4 & 46.9 & 37.2 & 15.0 & \\
\hline Fair & 48.8 & 42.3 & 49.1 & 56.3 & \\
\hline Poor/Very poor & 14.8 & 10.8 & 13.7 & 28.7 & \\
\hline Number of chronic diseases & & & & & $<0.001$ \\
\hline 1 & 49.3 & 81.6 & 51.7 & 0.0 & \\
\hline$\geq 2$ & 50.7 & 18.4 & 48.3 & 100.0 & \\
\hline
\end{tabular}

${ }^{1}$ Pearson's chi-squared test $p$-value; ${ }^{2}$ Mild/moderate: 1 to 7 units/week for women and 1 to 14 units/week for men; at risk intake: more than 7 units/week for women and more than 14 units /week for men; ${ }^{3}$ At least 150 minutes of light/moderate activity or 75 minutes of vigorous activity per week. 
Table 2. Distribution of food consumption markers and anthropometric indicators among Brazilian elderly persons with chronic diseases, according to the number of medications consumed. National Health Survey (2013).

\begin{tabular}{|c|c|c|c|c|c|}
\hline \multirow[t]{2}{*}{ Variables } & \multirow[t]{2}{*}{ Total $^{1}$} & \multicolumn{3}{|c|}{ Medication intake $^{1}$} & \multirow[t]{2}{*}{$P$-value ${ }^{2}$} \\
\hline & & None & 1 to 2 & 3 or more & \\
\hline Recommended intake of fruit and vegetables & & & & & 0.002 \\
\hline No & 74.5 & 80.6 & 73.7 & 70.2 & \\
\hline Yes & 25.5 & 19.4 & 26.3 & 29.8 & \\
\hline Regular intake of fish & & & & & 0.165 \\
\hline No & 42.9 & 45.4 & 43.0 & 38.2 & \\
\hline Yes & 57.1 & 54.6 & 57.0 & 61.8 & \\
\hline Regular intake of beans & & & & & 0.109 \\
\hline No & 28.2 & 28.3 & 27.4 & 33.0 & \\
\hline Yes & 71.8 & 71.7 & 72.6 & 67.0 & \\
\hline Regular intake of sweet foods & & & & & 0.002 \\
\hline No & 83.4 & 77.2 & 84.2 & 87.8 & \\
\hline Yes & 16.6 & 22.8 & 15.8 & 12.2 & \\
\hline Regular intake of soft drinks or artificial juices & & & & & 0.009 \\
\hline No & 88.3 & 84.0 & 89.2 & 89.7 & \\
\hline Yes & 11.7 & 16.0 & 10.8 & 10.3 & \\
\hline Milk intake & & & & & $<0.001$ \\
\hline Does not drink & 21.3 & 27.4 & 20.7 & 15.4 & \\
\hline Drinks skimmed or semi-skimmed milk & 21.5 & 12.6 & 22.3 & 31.0 & \\
\hline Drinks full-fat milk & 57.2 & 60.0 & 57.0 & 53.6 & \\
\hline Salt intake & & & & & 0.647 \\
\hline Adequate/low/very low & 92.9 & 91.8 & 93.1 & 93.3 & \\
\hline Very high/high & 7.1 & 8.2 & 6.9 & 6.7 & \\
\hline Intake of meat with excess fat & & & & & $<0.001$ \\
\hline No & 73.6 & 63.2 & 75.6 & 77.0 & \\
\hline Yes & 26.4 & 36.8 & 24.4 & 23.0 & \\
\hline Body mass index $\left(\mathrm{kg} / \mathrm{m}^{2}\right)^{3}$ & $27.3(5.1)$ & $25.9(5.3)$ & $27.4(5.0)$ & $28.2(5.1)$ & $<0.001$ \\
\hline Waist circumference $(\mathrm{cm})^{3}$ & $96.9(12.8)$ & $93.0(13.4)$ & $97.4(12.5)$ & $99.9(12.3)$ & $<0.001$ \\
\hline Waist-height ratio ${ }^{3}$ & $0.61(0.1)$ & $0.58(0.1)$ & $0.61(0.1)$ & $0.63(0.1)$ & $<0.001$ \\
\hline
\end{tabular}

${ }^{1}$ Values expressed as percentages, except where specified; ${ }^{2} p$-value of Pearson's Chi-squared test or linear regression F-test .; ${ }^{3}$ Values expressed as means (standard-deviation). 


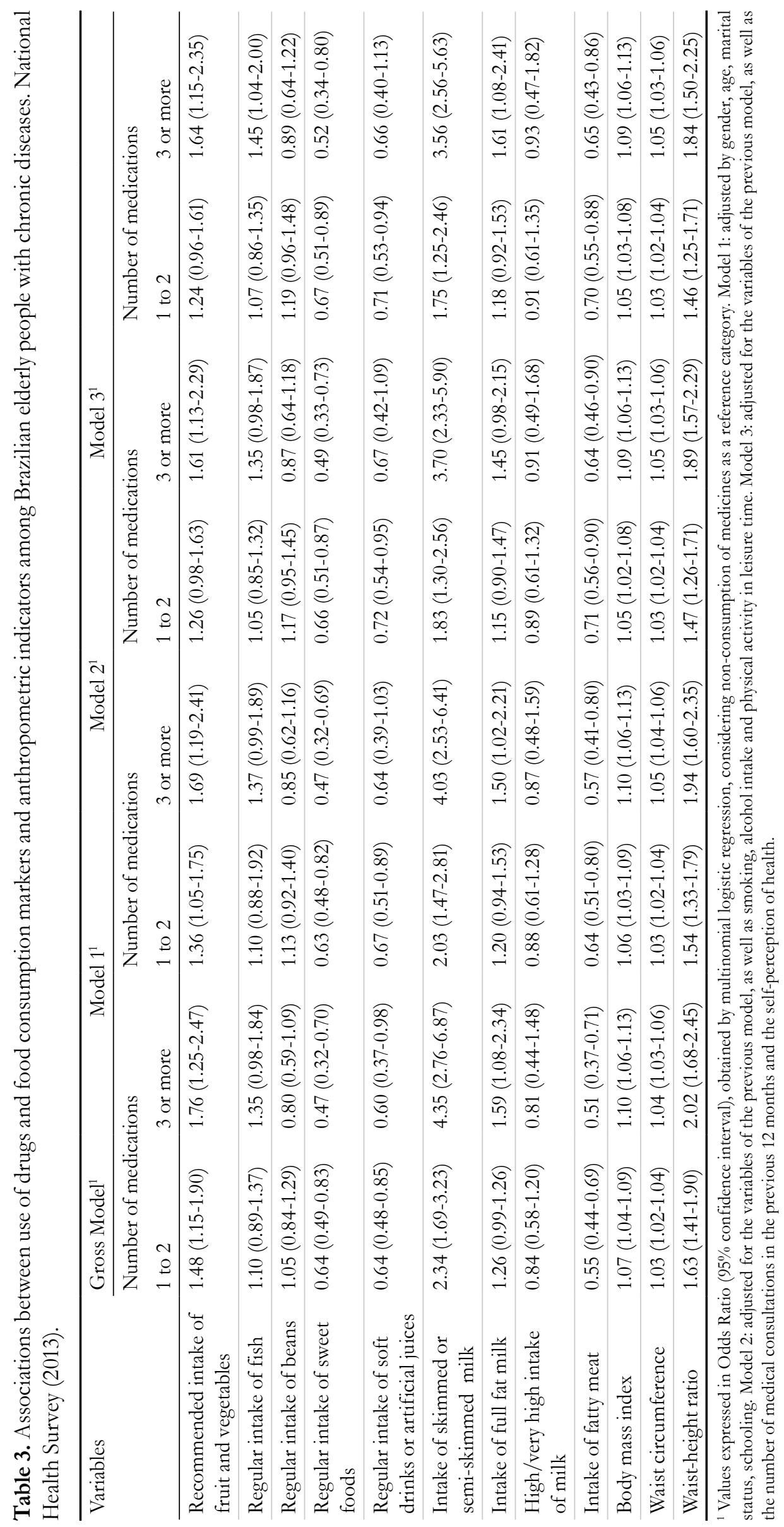




\section{DISCUSSION}

The results of the present study showed that $17.6 \%$ of elderly persons with CNCD did not take any medication for these diseases and $82.4 \%$ took medication for at least one of the diseases investigated. It was also generally observed that a greater use of medications was associated with more frequent intake of fruits and vegetables, fish and skimmed milk and less frequent consumption of sweet foods, soft drinks or artificial juices and fatty meat. In addition, elderly persons with the highest intake of medications had higher values for the anthropometric indicators evaluated.

Drug intake is high among Brazilian elderly persons, with consumption reaching between 2.1 and 4.7 medications per day ${ }^{17-19}$. This use has been reported to increase with age, similar to the findings of the present study ${ }^{20}$. It is known that some factors can contribute to the elevated use of medications in this population, such as non-adherence to nonpharmacological treatments for chronic diseases ${ }^{5}$, the practice of self-medication, the incorrect use of medications, receiving prescriptions from different doctors, and inadequate understanding of medication instructions, due to the similarity in color, size or shape of the same ${ }^{20}$. Regarding diet, which was evaluated by food intake markers, the results showed that the use of greater numbers of medications was associated with better quality of diet among elderly people with CNCD. In general, a higher frequency of consumption of fruits and vegetables, fish and milk (full fat, skimmed or semi-skimmed) and a lower frequency of consumption of sweet foods, soft drinks or artificial juices and fatty meat was observed. In contrast to these results, a study among elderly people living in rural areas in the United States found that the use of more medications was associated with a greater intake of foods rich in cholesterol, glucose, sodium and the lower consumption of fiber ${ }^{6}$. On the other hand, a study conducted with patients aged 50 years or above from a hospital in Rome, Italy, found that the average amounts of medication used were significantly lower in patients who were more likely to consume four or more spoonfuls per day of olive oil, fish, legumes and vegetables, and a moderate consumption of nuts ${ }^{21}$. Among elderly residents in Goiânia (Goias), who were users of the Unified
Health System, it was possible to observe a significant association between the use of multiple medications and reported dieting, although a significant specific association with the reported consumption of fruits and vegetables was not observed ${ }^{5}$.

Despite these divergences, Brazilian and nonBrazilian studies have observed changes in the diet of the elderly, possibly due to changes in their health and disease patterns, with an increase in vegetable intake and a lower consumption of processed and sweet products $^{12-24}$. In this sense, it is suggested that the group of elderly Brazilians with an increased use of medicines for chronic diseases may have been advised by health professionals to change their diet. This hypothesis is corroborated by the greater number of medical consultations among the elderly with a higher intake of medications, as observed in this study. These results therefore reinforce the need for health services to provide correct guidance on the use of medications and diet, considering the effects of interactions among these factors, which can lead to a reduction in the bioavailability of vitamins and minerals and significant nutritional deficits ${ }^{6}$.

The values of the anthropometric indicators used to evaluate the nutritional status of the elderly in this study were higher among elderly persons who reported using more medications. A review study found contrasting results regarding the association between medication use and nutritional status, describing populations where the greater use of medication was associated with weight loss and others where such use was related to weight gain. These differences may be related to the quality, quantity and variety of food to which the elderly are exposed, length of medication use and type of medication, as well as the adverse effects of the drugs ${ }^{4}$. However, similar to the findings of the present study, an analysis of elderly users of the Unified Health System found that BMI was directly proportional to the prevalence of medication use ${ }^{6}$. Our results therefore reinforce this evidence and add to it by demonstrating that three anthropometric indicators were consistently associated with the number of medications used by this population. This evidence, therefore, shows that not only the general body mass evaluated by BMI but also the concentration of abdominal fat, which is associated with higher metabolic risks, was associated with the intake of a greater number of medications in 
the elderly evaluated ${ }^{5}$, demonstrating the importance of actions aimed at the control of these diseases and reinforcing the hypothesis that the use of a greater number of medications and nutritional disorders are related in both directions ${ }^{2}$.

The consistent association between the number of medications used and the anthropometric indicators reveals the importance of monitoring the nutritional status of the elderly with CNCD by health services, as this evaluation can be carried out in a practical and noninvasive manner ${ }^{25}$, and that nutritional status may influence the treatment process of these diseases ${ }^{2}$. This is an important aspect to be considered by health services, since the results described in the present study point to a better quality of food among elderly people with a greater intake of medications, but still show important differences in relation to body composition, which should be considered in the planning of intervention actions.

This study presents some limitations, such as its cross-sectional nature, which does not allow a temporal relationship between the variables to be established. Information on the use of medication was self-reported, which may have introduced an information bias, although previous research has already demonstrated the adequate validity of these questions ${ }^{26,27}$. In addition, questions about medication

\section{REFERENCES}

1. Miranda GMD, Mendes AG, Silva ALA. O envelhecimento populacional brasileiro: desafios e consequências sociais atuais e futuras. Rev Bras Geriatr Gerontol. 2016;19(3):507-19.

2. Zadak Z, Hyspler R, Ticha A, Vlcek J. Polypharmacy and malnutrition. Curr Opin Clin Nutr Metab Care. 2013;16(1):50-5.

3. Little MO. Updates in nutrition and polypharmacy. Opin Clin Nutr Metab Care. 2018;21(1):4-9.

4. Jyrkkä J, Enlund H, Lavikainen P, Sulkava R, Hartikainen S. Association of polypharmacy with nutritional status, functional ability and cognitive capacity over a three-year period in an elderly population. Pharmacoepidemiol Drug Saf. 2011;20(5):514-22. use were linked to the medical diagnosis report for each disease considered in this study, which could underestimate the number of medications used, since the respondent may use more than one drug for each condition assessed. Despite these limitations, the present analysis employed a population-based structure, and used standardized procedures and trained interviewers to collect data, which ensured the internal validity of the study ${ }^{28}$.

\section{CONCLUSION}

In summary, the results suggest that the greater use of medications for chronic diseases among the Brazilian elderly was associated with a better quality diet, which may be attributed to the guidance of health professionals, but is still associated with higher values among the indicators, suggesting a higher frequency of overweight and/or obesity in this group, which may make it difficult to adequately control the chronic conditions in question. In view of this situation, the importance of the careful evaluation of the diet and nutritional status of elderly persons taking multiple medications for chronic diseases should be highlighted, as this practice can identify groups of greater vulnerability in relation to nutritional deficits, who should be continuously monitored by health teams aiming to adequately control these diseases.

5. Silveira EA, Dalastra L, Pagotto V. Polifarmácia, doenças crônicas e marcadores nutricionais em idosos. Rev Bras Epidemiol. 2014;17(4):818-29.

6. Heuberger RA, Caudell K. Polypharmacy and nutritional status in older adults: a cross-sectional study. Drugs Aging. 2011;28(4):315-23.

7. Agostini JV, Han L,Tinetti ME. The relationship between number of medications and weight loss or impaired balance in older adults. J Am Geriatr Soc. 2004;52(10):1719-23.

8. Jyrkkä J, Mursu J, Enlund H, Lönnroos E. Polypharmacy and nutricional status in elderly people. Curr Opin Clin Nutr Metab Care. 2012;15(1):1-6.

9. Fernandes DPS, Duarte MSL, Pessoa MC, Franceschini SDCC, Ribeiro AQ. Evaluation of diet quality of the elderly and associated factors. Arch Gerontol Geriatr. 2017;72:174-80. 
10. Instituto Brasileiro de Geografia e Estatística. Pesquisa Nacional de Saúde - 2013 [Internet]. Rio de Janeiro: IBGE; 2013 [acesso em 25 nov. 2017]. Disponível em: http://www.ibge.gov.br/home/ estatistica/populacao/pns/2013/

11. Instituto Brasileiro de Geografia e Estatística. Pesquisa Nacional de Saúde - 2013: percepção do estado de saúde, estilos de vida e doenças crônicas - Brasil, grandes regiões e unidades da Federação [Internet]. Rio de Janeiro: IBGE; 2014 [acesso em 25 nov. 2017]. Disponível em: ftp://ftp.ibge.gov.br/ PNS/2013/pns2013.pdf

12. Jaime PC, Stopa SR, Oliveira TP, Vieira ML, Szwarcwald CL, Malta DC. Prevalência e distribuição sociodemográfica de marcadores de alimentação saudável, Pesquisa Nacional de Saúde, Brasil 2013. Epidemiol Serv Saúde. 2015;24(2):267-76.

13. Claro RM, Santos MAS, Oliveira TP, Pereira CA, Szwarcwald CL, Malta DC. Consumo de alimentos não saudáveis relacionados a doenças crônicas não transmissíveis no Brasil: Pesquisa Nacional de Saúde, 2013. Epidemiol Serv Saúde. 2015;24(2):257-65.

14. Instituto Brasileiro de Geografia e Estatística. Pesquisa Nacional de Saúde - 2013: Manual de antropometria [Internet]. Rio de Janeiro: IBGE; 2013 [acesso em 25 nov. 2017]. Disponível em: https:// www.pns.icict.fiocruz.br/arquivos/Novos/Manual de Antropometria PDF.pdf

15. National institute on alcohol abuse and alcoholism (NIAAA). The physician's guide to helping patients with alcohol problem [Internet]. Washington, DC; 1995 [acesso em 28 nov. 2017]. Disponível em: http:// kobiljak.msu.edu/CAI/OST517/PhysicianGuide.html

16. World Health Organization. Recommended population levels of physical activity for health in Global Recommendations on Physical Activity for Health [Internet]. Geneva: WHO; 2010 [acesso em 01 maio 2018]. Disponível em: http://apps.who.int/iris/ bitstream/handle/10665/44399/9789241599979_eng. pdf;jsessionid=3CF6B32C2EF6901F0A3A0B1C 638DE915? sequence $=1$

17. Loyola Filho AI, Uchoa E, Lima-Costa MF. Estudo epidemiológico de base populacional sobre uso de medicamentos entre idosos na Região Metropolitana de Belo Horizonte, Minas Gerais, Brasil. Cad Saúde Pública. 2006;22(12):2657-67.

18. Pereira KG, Peres MA, Iop D, Boing AC, Boing AF, Aziz M, et al. Polifarmácia em idosos: um estudo de base populacional. Rev Bras Epidemiol. 2017;20(2):335-44.
19. Ribas C, de Oliveira KR. Perfil dos medicamentos prescritos para idosos em uma Unidade Básica de Saúde do município de Ijuí-RS. Rev Bras Geriatr Gerontol. 2014;17(1):99-114.

20. Hajjar ER, Cafiero AC, Hanlon JT. Polypharmacy in elderly patients. Am J Geriatr Pharmacother. 2007;5(4):345-51.

21. Vicinanza R, Troisi G, Cangemi R, De Martino MU, Pastori D, Bernardini S, et al. Aging and adherence to the mediterranean diet: relationship with cardiometabolic disorders and polypharmacy. J Nutr Health Aging. 2018;22(1):73-81.

22. Doubova SV, Sánchez-García S, Infante-Castañeda C, Pérez-Cuevas R. Factors associated with regular physical exercise and consumption of fruits and vegetables among mexican older adults. BMC Public Health. 2016;16:1-14.

23. Jyväkorpi SK, Pitkälä KH, Puranen TM, Björkman MP, Kautiainen H, Strandberg TE, et al. High proportions of older people with normal nutritional status have poor protein intake and low diet quality. Arch Gerontol Geriatr. 2016;67:40-5.

24. Monteiro LS, Hassan BK, Estima CCP, Souza AM, Junior Verly E, Sichieri R, et al. Consumo alimentar segundo os dias da semana: Inquérito Nacional de Alimentação, 2008-2009. Rev Saúde Pública. 2017;51:1-11.

25. World Health Organization. Physical Status: the use and interpretation of anthropometry. Report of a WHO expert committee [Internet]. Geneva: WHO; 1995 [acesso em 25 nov. 2017]. Disponível em: http:// apps.who.int/iris/bitstream/handle/10665/37003/ WHO_TRS_854.pdf?sequence $=1$ \&isAllowed $=\mathrm{y}$

26. Chun H,Kim IH,Min KD. Accuracy of Self-reported Hypertension, Diabetes, and Hypercholesterolemia: analysis of a Representative Sample of Korean older adults. Osong Public Health Res Perspect. 2016;7(2):108-15.

27. Leggett LE, Khadaroo RG, Holroyd-Leduc J, Lorenzetti DL, Hanson H, Wagg A, et al. Measuring Resource Utilization: a systematic review of validated Self-Reported Questionnaires. Medicine (Baltimore). 2016;95(10):1-9.

28. Szwarcwald CL, Malta DC, Pereira CA, Vieira MLFP, Conde WL, Souza Júnior PRB, et al. Pesquisa Nacional de Saúde no Brasil: concepção e metodologia de aplicação. Ciênc Saúde Colet. 2014;19(2):333-42. 